\title{
Effects of different test apparati and heating procedures on the bond properties of post-installed rebar connections under elevated temperatures
}

\author{
G. Muciaccia $^{1} *$. D. Dongo Navarrete ${ }^{1}$. \\ N. Pinoteau ${ }^{2}$. R. Mége ${ }^{2}$
}

Received: date / Accepted: date

\begin{abstract}
The use of chemical bonds to fasten reinforcement bars in existing concrete structures has been widely developed in the previous years, showing in many cases higher bond values compared to cast in rebars due to better performance of the adhesive mortar. However, at elevated temperatures the concrete-adhesive bond tends to weaken endangering the construction under a fire situation.

The paper presents the result of an experimental campaign carried out at Scientific and Technical Center of Building (CSTB) and Politecnico di Milano laboratories on a post-installed connection using vinyl-ester polymer. This paper aims to investigate the behavior of rebar connections through chemical resin when subjected to high temperatures, with particular emphasis on the effects of water vaporization in the concrete and on the influence of heating procedures on the mortar post-curing. Two different pull-out test procedures were adopted, differentiating each other for the loading and heating sequences. Results showed that specimens with the same water content may present different thermal gradients; however, comparable mean temperatures along the bar are detected for the same values of applied load. Moreover, for a given temperature, the increase of bond strength with exposure time showed a convergence towards an asymptotic value.
\end{abstract}

Keywords Post-installed rebar · Water vaporization · Pull-out · Post-curing

1 Department of Civil and Environmental Engineering, Politecnico di Milano.

2 Université Paris-Est, Centre Scientifique et Technique du Bâtiment.

\section{Introduction}

Reinforcement bars in concrete members can be divided into two categories: castin-place and post-installed. Post-installed rebars are an alternative to cast-in bars and they are preferable in many situations due to their good flexibility in use. Additionally, in many cases the bond strength of post-installed rebars is higher compared to cast-in rebars due to better performance of the adhesive mortar.

*corresponding author E-mail: giovanni.muciaccia@polimi.it 
However, few studies have been carried out to establish the behavior of such connections under elevated temperatures [15][7][11][18]. In particular, in such conditions, four different phenomena can be highlighted:

- The resistance and stiffness of the adhesive tend to decrease progressively with temperature. The EAD 330087 [12] provides a test and assesment method to determine the reduction factor $k_{f i}(\theta)$ associated with the reduction of bond strength due to the effects of temperature.

- The stress/strain properties of polymeric adhesives vary considerably with the temperature range between $20^{\circ} \mathrm{C}$ and $150^{\circ} \mathrm{C}$ [1] in comparison with steel or concrete properties alone. During injection of the adhesive, both mortar components react together to achieve a three dimensional cross-linked network. At ambient temperature the reaction is never complete. By heating the material, molecular mobility is restored to unreacted polymeric groups which increases the degree of the reaction [5]. This results in a densification of the adhesive structure generally yielding higher mechanical properties (depending on the chemistry). A longer thermal exposure in a stabilized temperature test favors strengthening of the material through post-curing [16].

- When an adhesive material is subjected to a constant load, it experiences a time-dependent increase in strain. This well known phenomenon of deformation under load with time is referred to as creep [19]. In addition, the effect of sustained load reduces the bond resistance. Studies have shown that temperature increases the creep behavior [5].

- Due to temperature increase near $100^{\circ} \mathrm{C}$ water vaporization occurs in concrete [7]. This induces hydric movements at the concrete-mortar interface. Some authors have shown that high moisture contents may decrease polymeric resistance [2], hence weaken the bond.

Moreover, the current assessment documents [12] merely provide a minimum heating rate $\left(5^{\circ} \mathrm{C} / \mathrm{min}\right)$ to be applied during testing. However, since post-cure, creep and water diffusion depend on time and temperature, different bond strength may be found if different heating rates are used.

The goal of this paper is to study the influence of different testing apparati and heating procedures on the characterization of the bond strength $\tau_{b}$ through pullout tests for which the concrete surface was confined, performed at elevated temperature on specimens made up by a steel rebar embedded in a concrete cylinder. By adopting electrical ovens, two different pull-out procedures are applied with differences in terms of heating and loading sequences. The experimental campaign took place at Scientific and Technical Center of Building (hereinafter 'CSTB') and Politecnico di Milano laboratory of testing materials (hereinafter 'PoliMI'). The investigated polymer is a vinyl-ester bonding agent currently qualified in Europe for post-installed concrete-to-concrete connections at ambient temperature (according to [4][12]). 

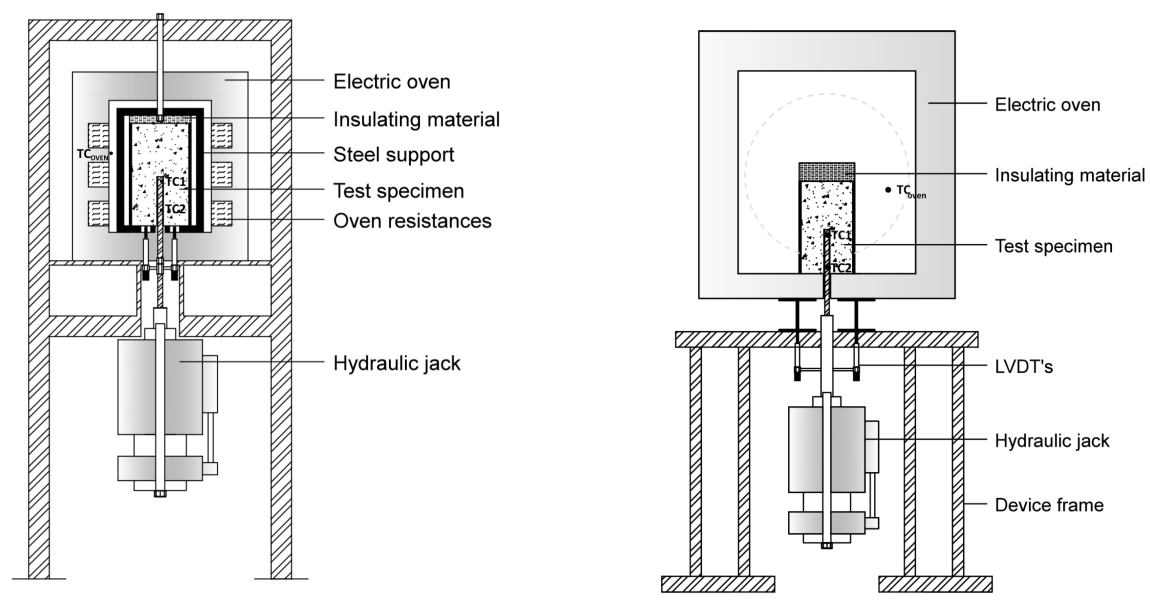

Fig. 1: CSTB (top) and PoliMI (bottom) heating devices

\section{Materials and methods}

\subsection{CSTB set up}

\subsubsection{Heating device}

A cylindrical electric oven equipped with 3 rings of resistance element heaters on its lateral sides was used. This allowed to ensure an uniform and reproducible distribution of temperature along the lateral borders of the sample during the test. The rebar was oriented downwards in the device with a hydraulic jack located beneath the oven (Figure 1, top). For the acquisition of the oven temperature, a thermocouple in direct contact with one of the resistance was used $\left(T C_{\text {oven }}\right)$.

\subsubsection{Test specimen}

Concrete cylinders of $16 \mathrm{~cm}$ diameter and $25 \mathrm{~cm}$ height, encased in a $2 \mathrm{~mm}$ thickness steel tube were used. The cylinders were cured at least 244 days in laboratory conditions (after a curing of 28 days at ambient temperature). The concrete class was C20/25 in accordance with the EAD 330087 [12] and EOTA TR 023 [4]. Mix components of concrete are reported in Table 1 . The rebars were $12 \mathrm{~mm}$ Diwidag type, the Young's modulus (measured by tensile tests) was $E_{s}=222 \mathrm{GPa}$ [17]. The cleaning procedure was performed according to the resin supplier's indications.

The drilled hole had a depth of $120 \mathrm{~mm}$ with a diameter of $16 \mathrm{~mm}$. For temperature acquisition, two thermocouples type $\mathrm{K}$ were placed along the embedded part in accordance with [12]:

- TC1 placed at the deepest part of the anchor;

- TC2 at $10 \mathrm{~mm}$ from the concrete surface.

Finally, the displacements at the rebar loaded end were monitored using three LVDTs with a measurement range of $5 \mathrm{~mm}$ and a resolution of $0.02 \mathrm{~mm}$, placed at 
$120^{\circ}$ around the rebar. The distance between the concrete surface and the LVDT connection on the rebar was $100 \mathrm{~mm}$. Figure 2 shows the arrangement of LVDTs at the bottom of the specimen.

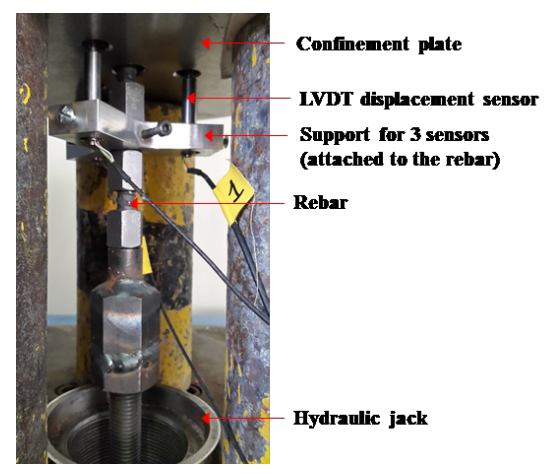

Fig. 2: Detail of the displacement measurements

\subsection{PoliMI set up}

\subsubsection{Heating device}

An electrical oven presenting a capacity of $850^{\circ} \mathrm{C}$ was used (Figure 1, bottom). The specimen was set inside the oven, then a series of four additional layers (insulating material + steel plate + insulating material + steel plate) were interposed between the bottom face of the specimen and the bottom side of the chamber to both ensure a proper insulation and an even distribution of the contact stresses. The chamber was successively closed by means of additional insulating material.

\subsubsection{Test specimen}

Concrete of class C20/25 was produced according to the specifications of the EAD 330087 [12] and EOTA TR 023 [4]. Mix-components of concrete are reported in Table 1. The specimen was identical to CSTB's, except for the rebar type, which was a standard B450C 12mm deformed bar. Additionally, only two LVDTs arranged symmetrically on the rebar sides were used.

\subsection{Test procedures}

For the experimental campaign, two different pull-out procedures were adopted.

- Constant load (CL) tests: The tests were performed by applying an increasing tensile load of $0.05 \mathrm{kN} / \mathrm{s}$ on the rebar until reaching the desired value of target load. Once reached the required load level, the temperature in the oven was increased while the load was kept constant. The test continued until pull-out of the rebar occurred. 
Table 1: Mix components at CSTB \& PoliMI

\begin{tabular}{|c|c|}
\hline \multicolumn{2}{|l|}{ CSTB } \\
\hline Cement CEM II/B-LL 32,5 R CP2 $\left(\mathrm{kg} / \mathrm{m}^{3}\right)$ & 320 \\
\hline Aggregate $\left(\mathrm{kg} / \mathrm{m}^{3}\right)$ & \\
\hline Bouaffle Recompos (0-8) & 880 \\
\hline RC La Brosse (4-14) & 792 \\
\hline RC La Brosse (4-20) & 88 \\
\hline Total aggregate $\left(\mathrm{kg} / \mathrm{m}^{3}\right)$ & 1760 \\
\hline Water $\left(l / m^{3}\right)$ & 227 \\
\hline Water/cement & 0.71 \\
\hline \multicolumn{2}{|l|}{ PoliMI } \\
\hline Cement CEM I $52,5 \mathrm{R}\left(\mathrm{kg} / \mathrm{m}^{3}\right)$ & 250 \\
\hline Aggregate $\left(\mathrm{kg} / \mathrm{m}^{3}\right)$ & \\
\hline Fine $(0-4)$ & 300 \\
\hline Fine $(0-8)$ & 700 \\
\hline Coarse $(8-15)$ & 270 \\
\hline Coarse $(15-25)$ & 600 \\
\hline Total aggregate $\left(\mathrm{kg} / \mathrm{m}^{3}\right)$ & 1870 \\
\hline Superplasticizer (\% on cement mass) & 0 \\
\hline Water $\left(l / m^{3}\right)$ & 185 \\
\hline Water/cement & 0.74 \\
\hline
\end{tabular}

- Stabilized temperature (ST) tests: The tests were performed by heating the oven until reaching the value of target temperature along the rebar, with no load applied on the rebar. While keeping the temperature constant, the load was subsequently applied to the rebar at a constant displacement rate $(0.05$ $\mathrm{mm} / \mathrm{s}$ ), such that pull-out occurred between 1 and 3 minutes.

\subsection{Test program}

The following approach was followed:

1. Constant load tests were performed recording, for each sample, the failure temperatures (TC1 and TC2) along the bar and the rebar displacement. The values of applied load correspond to uniform bond stress values equal to 4.0, 6.0, 8.0, 9.0, 10.0 and 11.9 MPa. The value of 9.0 MPa was included to strengthen the comparison between test procedures (constant load versus stabilized temperature) in the range between 75 and $80{ }^{\circ} \mathrm{C}$ as will be presented in the conclusions from Figure 9. For all the specimens the bonded length was equal to $120 \mathrm{~mm}$. Constant load tests were carried out according to the current EAD procedure [12] both at CSTB and PoliMI in order to verify inter-laboratory repeatability.

2. Once failure temperatures were associated to applied load values, a load level corresponding to an applied uniform bond equal to $9.0 \mathrm{MPa}$ (associated to a temperature at failure around $80^{\circ} \mathrm{C}$ in constant load tests) was used as reference temperature for the stabilized temperature tests. Stabilized temperature tests were performed targeting such temperature, but changing the heating 
rate. Seven tests in total were carried out, varying the heating rate from a minimum of $0.5^{\circ} \mathrm{C}$ per minute to a maximum of $15.0^{\circ} \mathrm{C}$ per minute. Heating rates and total exposure time are reported in Figure 9 for each test. These tests were carried out at CSTB only.

For all the tests, measurements of temperatures, loads and displacements were acquired automatically at $4 \mathrm{~Hz}$.

\section{Experimental results and discussion}

Initially, a comparison between results obtained at CSTB and PoliMI is presented. Successively, the effects of different heating rates are investigated and discussed.

\subsection{Inter-laboratory comparison}

The oven heating rates were set in order to obtain a consistent comparison of results despite the different geometries and heating characteristics of the ovens at the two laboratories. To such scope, an initial analysis was carried out to define heating rates for the oven (air side) which could correspond to the same temperature increase rate at thermocouples locations. As a consequence, heating rates were set to $10^{\circ} \mathrm{C} / \mathrm{min}$ for PoliMI and $15^{\circ} \mathrm{C} / \mathrm{min}$ for CSTB, which correspond to average heating rates at the bond location equal to $1.9^{\circ} \mathrm{C} / \mathrm{min}$ for PoliMI and $2.0^{\circ} \mathrm{C} / \mathrm{min}$ for $\mathrm{CSTB}$ in the temperature range between 30 to $80^{\circ} \mathrm{C}$. Outside of such range, slghtly higher differences were detected.

Test results at CL are summarized in Table 2, which reports the sample reference code, the applied load $N_{\text {sust }}$, the average bond strength $\tau_{m}$, the temperature at failure at bond location $T_{W, f}$, the duration of the test (measured from the moment in which the load attained its target value), and temperature values at both TC1 and TC2 location at failure. The temperature $T_{W, f}$ is calculated as the weighted average of TC1 and TC2 in accordance with the assessment criteria of EAD 330087 [12], as equal to $1 / 3$ of the maximum temperature plus $2 / 3$ of the minimum temperature (among TC1 and TC2).

The average bond strength $\tau_{m}$ is calculated assuming a uniform bond stress distribution along the rebar as:

$$
\tau_{m}=\frac{N_{\text {sust }}}{\pi \cdot d \cdot l_{v}}
$$

where $d$ is the diameter of the steel bar and $l_{v}$ is the length of the embedded steel bar.

Finally, Figure 3 reports the variation of the bond strength as a function of the weighted average temperature for the investigated bonding agent. The bond strength at room ambient temperature was previously evaluated and it is equal to $13.3 \mathrm{MPa}$. Power trend curves are used to describe the decay of bond strength with temperature and they present an accurate fitting of the data points with a coefficient of correlation $R^{2}$ around 0.97 in both cases. The thermal gradients of CSTB tests appear higher especially near $100^{\circ} \mathrm{C}$ where the difference between TC1 and TC2 can reach $50^{\circ} \mathrm{C}$ (Figure 3). However, very low differences are observed 
Table 2: Constant load tests results

\begin{tabular}{ccccccc}
\hline Code & $\mathbf{N}_{\text {sust }}$ & $\begin{array}{c}\tau_{\mathbf{m}} \\
(\mathbf{M P a})\end{array}$ & $\begin{array}{c}\mathbf{T}_{\mathbf{W}, \mathbf{f}} \\
\left({ }^{\circ} \mathbf{C}\right)\end{array}$ & $\begin{array}{c}\text { Duration } \\
(\mathbf{k N i n})\end{array}$ & $\begin{array}{c}\mathbf{T C}_{\mathbf{1}} \\
\left({ }^{\circ} \mathbf{C}\right)\end{array}$ & $\begin{array}{c}\mathbf{T C}_{\mathbf{2}} \\
\left({ }^{\circ} \mathbf{C}\right)\end{array}$ \\
\hline Cstb_CL_01 & 54.0 & 11.9 & 49 & 48 & 53 & 47 \\
Cstb_CL_02 & 36.2 & 8.0 & 90 & 65 & 103 & 83 \\
Cstb_CL_03 & 45.2 & 10.0 & 52 & 55 & 56 & 50 \\
Cstb_CL_04 & 18.1 & 4.0 & 151 & 115 & 139 & 173 \\
Cstb_CL_05 & 27.1 & 6.0 & 114 & 76 & 138 & 102 \\
Cstb_CL_06 & 40.9 & 9.0 & 78 & 63 & 89 & 73 \\
\hline PM_CL_01 & 18.1 & 4.0 & 142 & 95 & 154 & 136 \\
PM_CL_02 & 18.1 & 4.0 & 161 & 116 & 163 & 159 \\
PM_CL_03 & 27.0 & 6.0 & 124 & 65 & 125 & 123 \\
PM_CL_04 & 27.0 & 6.0 & 113 & 58 & 124 & 107 \\
PM_CL_05 & 54.0 & 11.9 & 47 & 41 & 51 & 45 \\
PM_CL_06 & 54.0 & 11.9 & 47 & 32 & 47 & 47 \\
PM_CL_07 & 40.7 & 9.0 & 76 & 60 & 74 & 76 \\
PM_CL_08 & 22.5 & 5.0 & 129 & 71 & 130 & 128 \\
PM_CL_09 & 36.0 & 8.0 & 79 & 61 & 81 & 78 \\
PM_CL_10 & 45.0 & 10.0 & 48 & 37 & 51 & 48 \\
\hline
\end{tabular}

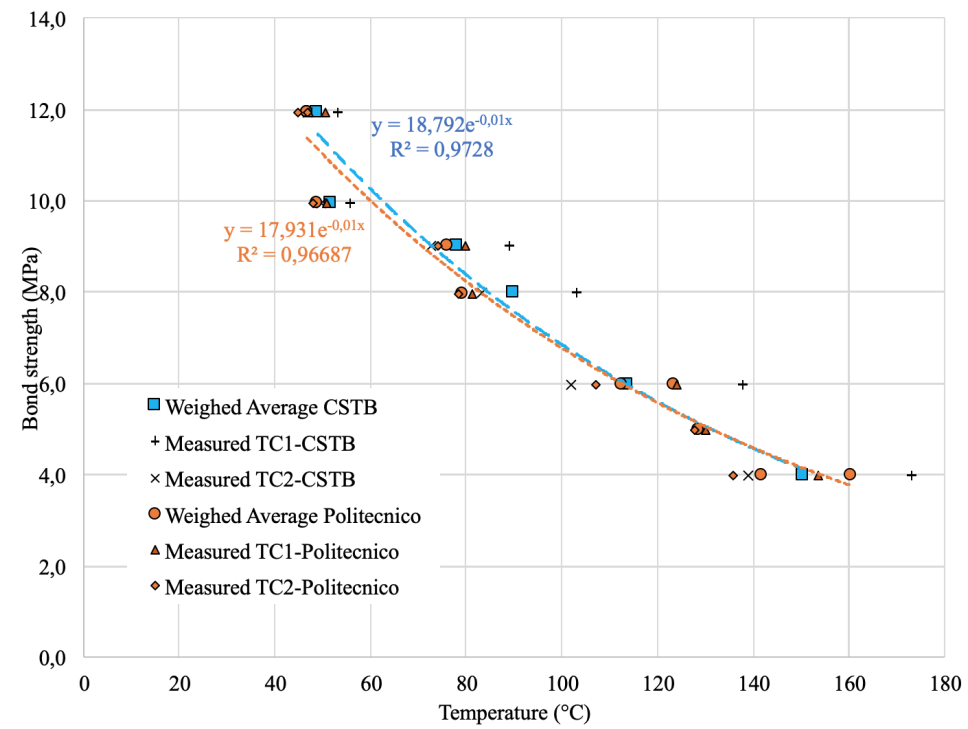

Fig. 3: Variation of bond strength vs temperature for vinyl-ester mortar for constant load tests

when referring to the weighted average temperatures, as the trend curves (generally used for the product evaluation [12]) are almost completely superimposed. As an example, at $50^{\circ} \mathrm{C}$, such difference is lower than $5 \%$. 

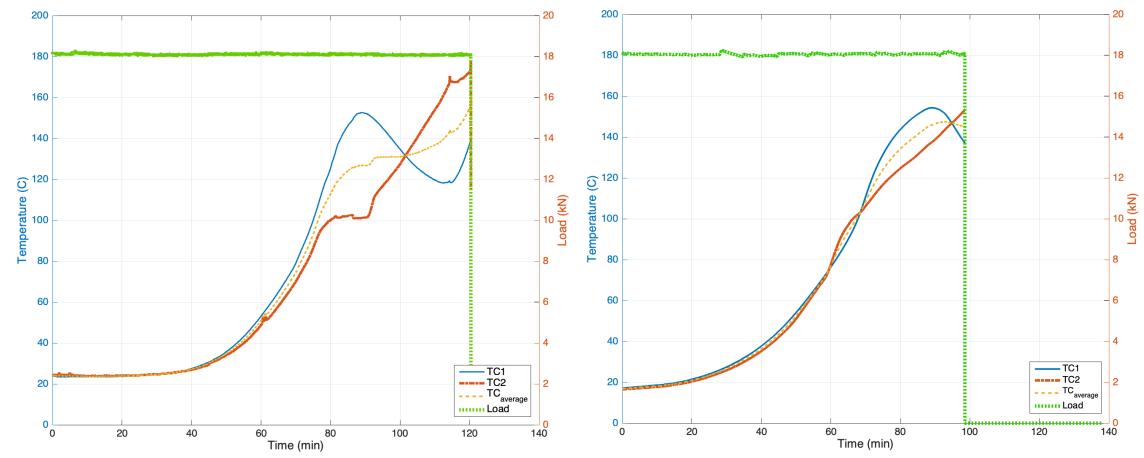

Fig. 4: Evolution of temperature with time in a constant load test for the same load level at CSTB (left) and PoliMI (right)

\subsubsection{Temperatures evolution}

Figure 4 shows the temperature evolution with time during two constant load tests carried out at the same load level $(18.1 \mathrm{kN}$ - taken as an example) in both laboratories. The average bond temperature between TC1 and TC2 is also represented. The drop in the applied load is associated to pull-out of the bar, which in its turn is associated to the corresponding temperature at failure.

It is noticed how the temperature evolution at TC1 and TC2 is not the same for the two laboratories. As for the CSTB tests, when reaching a temperature near $100^{\circ} \mathrm{C}$, the thermocouple near the surface (TC2) shows a temperature plateau for a few minutes. In the core of the cylinder (TC1), the temperature continues to increase until approximately $150^{\circ} \mathrm{C}$, where it reaches a maximum. It then decreases for a few minutes to finally start increasing again. This can be attributed to the water vaporization in the specimen that does not occur at the same temperature along the specimen.

Such effect was already observed by the authors in the past in a different experimental campaign. As discussed in details in Pinoteau et al. [7], pressure near to the concrete surface is close to the atmospheric one and it favors water vaporization close to $100^{\circ} \mathrm{C}$, slowing down temperature increase in the near-surface area of the bond and diffusing water towards the center of the cylinder (where vaporization has not yet been initiated). Consequently, the center of the cylinder is subjected to higher pressures (due to confinement) and to slower heating (due to its distance from exposed surface): liquid water is confined in this area in a thermodynamically stable state $[6,16]$. The temperature decrease in the core is then attributed to a pressure decrease caused by an increase of permeability that might be due to interfacial cracking of the concrete and the evacuation of water in the peripheral zones [7].

Use of the water phase diagram (Figure 5) allows to estimate the pressure in the core by knowing the temperature at which vaporization occurs. It is found that pressure in the core increased until approximately 4.5 bar $(0.45 \mathrm{MPa})$ while near the surface it remains at 1 bar $(0,1 \mathrm{MPa})$. These values present the same order of magnitude as pressure measurements (between 0 and $1 \mathrm{MPa}$ ) performed in previous studies [13]. Such intensity of pressure in the core may induce spalling, 
as it was noted in some CSTB samples which split suddenly inside the steel cylinder. In such cases the average temperature along the bond reached values above $130^{\circ} \mathrm{C}$. Even though the concrete tensile strength is higher than the estimated pore pressure (it can be assumed as equal to $2.2 \mathrm{MPa}$ by adopting the Eurocode 2 approach [3]), a direct comparison is not appropriate because the tensile strength is not a punctual property of concrete. Therefore, spalling can occur because favored by effects of thermo-mechanical and thermo-hygrometric processes, in addition to thermal expansion of concrete, as observed in a few cases at CSTB. In addition, previous studies [10] have shown that also w/c ratio, heating rate, water content and type of aggregate may influence concrete spalling.

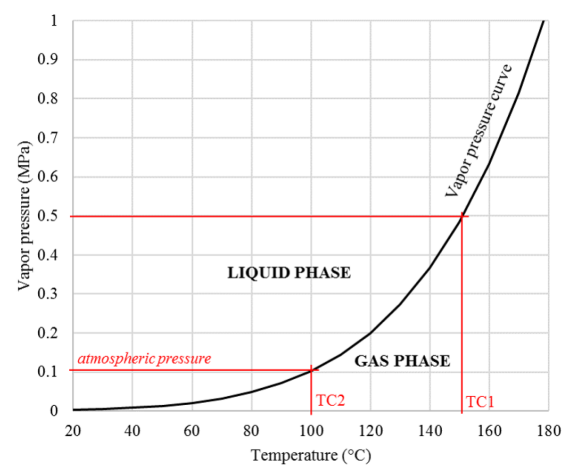

Fig. 5: Estimated water pressure as a function of the temperature at different thermocouples location

\subsubsection{Water content}

The influence of water vaporization can be noticed for tests where failure occured before the average bond temperature reached $100^{\circ} \mathrm{C}$. For such tests, the thermal gradients (temperature difference $\Delta T$ between $\mathrm{TC} 1$ and $\mathrm{TC} 2$ ) at failure are reported in Table 3. CSTB always presents higher gradients. In particular, when arriving to temperatures around $80^{\circ} \mathrm{C}$, CSTB gradients are almost 4 times those at PoliMI's (see CSTB_CL_02 vs PM_CL_09).

In order to verify if such difference was influenced by higher water content in CSTB mix design (see Table 1), tests for the characterization of the water loss were carried out for both mixes. The specimens were left drying inside an oven at $80^{\circ} \mathrm{C}$ and were weighted regularly through a time period of one month. Mass evolution allows to confirm the time of stabilization. Once the mass stabilizes, the evolution of the water content is determined. The curve reported in Fig. 6 is plotted according to Equation (2).

$$
m(t)=\frac{m_{\text {measured }}(t)}{m_{i}} \cdot 100 \%
$$

Where $m_{\text {measured }}(t)$ is the measured mass and $m_{i}$ is the initial mass. 
Table 3: Temperatures comparison

\begin{tabular}{ccccc}
\hline $\begin{array}{c}\text { Code } \\
(-)\end{array}$ & $\begin{array}{c}\mathbf{T}_{\mathbf{W}, \mathbf{f}}^{\circ} \\
\left({ }^{\circ} \mathbf{C}\right)\end{array}$ & $\begin{array}{c}\boldsymbol{\Delta} \mathbf{T} \\
\left({ }^{\circ} \mathbf{C}\right)\end{array}$ & $\begin{array}{c}\mathbf{T C}_{\mathbf{1}} \\
\left({ }^{\circ} \mathbf{C}\right)\end{array}$ & $\begin{array}{c}\mathbf{T C}_{\mathbf{2}} \\
\left({ }^{\circ} \mathbf{C}\right)\end{array}$ \\
\hline Cstb_CL_01 & 49 & 9 & 53 & 47 \\
PM_CL_05 & 47 & 6 & 51 & 45 \\
\hline Cstb_CL_03 & 52 & 7 & 56 & 50 \\
PM_CL_10 & 49 & 4 & 51 & 48 \\
\hline Cstb_CL_06 & 78 & 16 & 90 & 73 \\
PM_CL_07 & 76 & 6 & 74 & 76 \\
\hline Cstb_CL_02 & 90 & 20 & 103 & 83 \\
PM_CL_09 & 79 & 5 & 81 & 78 \\
\hline
\end{tabular}

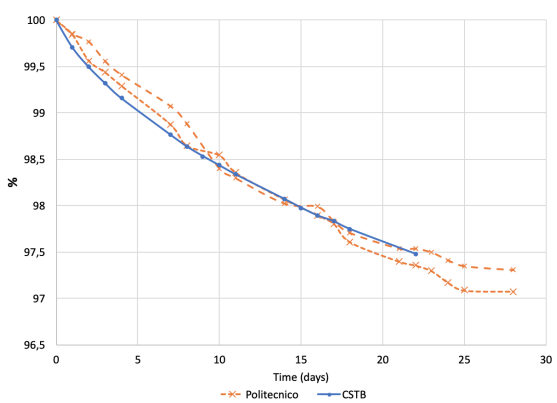

Fig. 6: Concrete mass loss

It is observed how both laboratories present a loss of water around $2.5 \%$. This can be explained due to different cement type used in the laboratories (CEM I at PoliMI and CEM II at CSTB), needing different water for the cement hydration and so leaving approximately the same amount of free water after 22 days which is then lost during the drying process.

Lastly, mercury intrusion porosimetry tests were performed in order to check if a different porosity of the specimens could justify the different thermal gradient. Test results are shown in Fig. 7 and they show a higher average pore diameter in CSTB specimens $(0.0879 \mu \mathrm{m}$ against $0.0665 \mu \mathrm{m}$ at PoliMI), as well as a higher porosity (17.69\% against $14.04 \%)$. Such results suggests that the water diffusion mechanism are different in the two concretes and they may lead to differences in temperature gradients, as detected during testing.

\subsection{Effects of heating procedure}

It is premised that, as most structural adhesives on the market, adhesion is achieved by mixing a resin with a hardener. Both components react in order to achieve a tridimensional cross linked network. At ambient temperature, molecules inside the polymers start to react making the material hardening; nevertheless, the reaction rate significantly decreases once the molecular cross-linking reaches a certain degree making the material a gel which highly reduces molecular mobility 

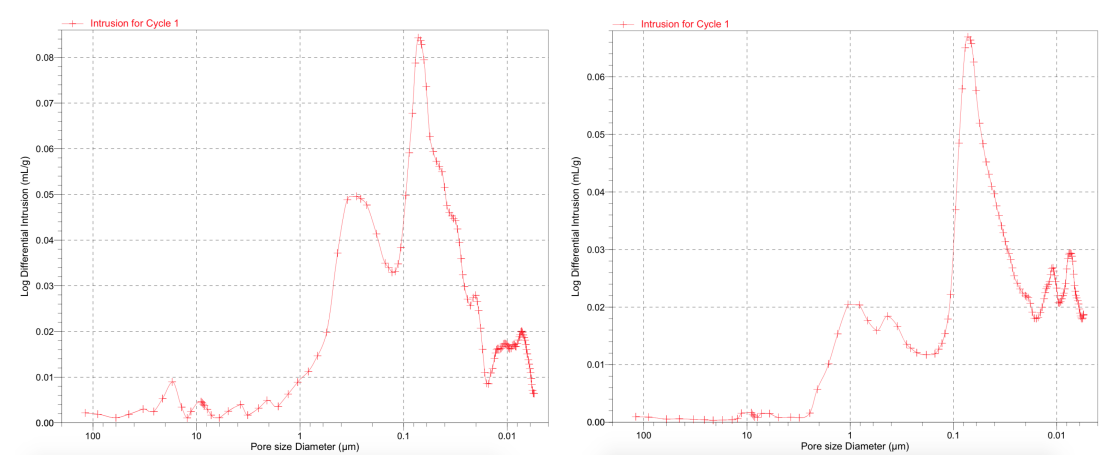

Fig. 7: Mercury intrusion porosimetry results for CSTB (left) and PoliMI (right) concrete mixes

and therefore prohibits accessibility between reactive groups. However, when energy in form of temperature is applied to the system, molecular mobility is favored and density of the cross-linked network increases thus increasing the strength of the material. Temperature increase has then the effect of restoring molecular mobility; then unreacted chains may participate in increasing the cross-linking degree which tends to strengthen the material [11][5] and they may 'smooth' the bond degradation induced by temperature.

Stabilized temperature (ST) tests were then carried out changing the heating rate till reaching the desired target temperature prior to load application. In order to avoid phenomena of water vaporization, once known the $\tau_{m}(\theta)$ curve, ST tests were performed targeting $80{ }^{\circ} \mathrm{C}$ temperature

\subsubsection{Stabilized temperature tests results}

For ST tests, Figure 8 reports the average bond stress as a function of the average displacement for ST tests in addition to the reference CL test for the same temperature. By comparing Cstb_CL_06 with ST_01 (both tests performed with a $15^{\circ} \mathrm{C} / \mathrm{min}$ heating rate), no significant change in bond strength $(0.2 \mathrm{MPa})$ is noticeable. The slope of the CL test appears to be higher than the ones of the stabilized temperature tests. This can be caused by the fact that load application in the CL test is applied at $20^{\circ} \mathrm{C}$ (before the heating starts), while for the ST tests the load is applied at $80^{\circ} \mathrm{C}$ and the stiffness of the mortar is higher at $20^{\circ} \mathrm{C}$ than at higher temperatures.

For higher durations the initial slope does not change, while an increase in the bond strength is detected. As the exposure time increases, the slip at the peak load also tends to increase. This is mainly caused by a change of curvature (starting around $8 \mathrm{MPa}$ ) before reaching the peak. This area of the behavior law is attributed to the progressive damage propagating from the beginning of the bond (near the surface where stress are higher) towards the deeper part of the bond [14].

By comparing results of ST tests (Figure 9, left), it is shown that the bond strength tends to present higher values for tests with a lower heating rate, which provides more time to the mortar to post-cure. As previously mentioned, this 
is probably due to an increase in the density of the cross-linked network, which results in a bond strengthening.

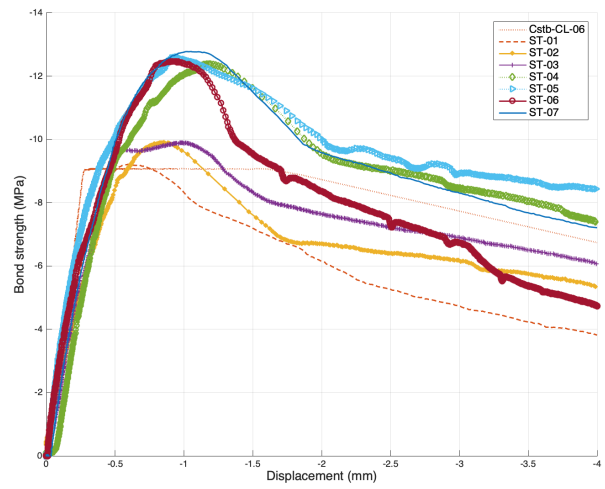

Fig. 8: Comparison among bond vs displacement curves for different test regimes at the same target temperature

By representing the bond strength as a function of the total stabilization time (Figure 9, right), it is observed how it increases and converges towards an asymptotic value. Such resistance plateau corresponds to the maximal cross-linking degree that may be achieved at $80^{\circ} \mathrm{C}$. The evolution of tensile resistance can be described by the Equation 3, developed by Moussa \& al. [9] and applied by Mishels $\&$ al. [14] on autocatalytic adhesives cured at room temperature. The model describes the material gaining resistance with an increasing rate in the first part due to the densification of the cross-linked network followed by a plateau in the last part. The fitting of the analytical function was carried out on the parameters $t_{m}$ and $s$ by minimizing the quadratic sum of the residues.

$$
\tau_{m}(t)=\frac{\tau_{m, 0}-\tau_{m, \infty}}{1+\left(\frac{t}{t_{m}}\right)^{s}}+\tau_{m, \infty}
$$
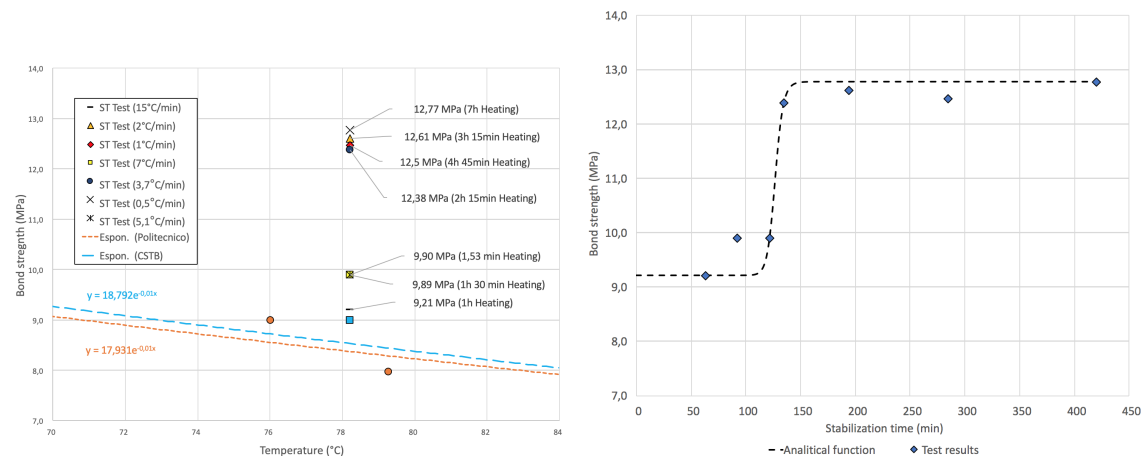

Fig. 9: Bond strength variation as a function of heating time 
Where:

- $\tau_{m, 0}$ is the bond strength with the fastest heating rate (equal to $9.2 \mathrm{MPa}$ );

- $\tau_{m, \infty}$ is the bond strength corresponding to a fully cured material (equal to $12.8 \mathrm{MPa})$;

$-t_{m}$ is the time needed to arrive at half of the maximal bond strength $\left(\tau_{m, \infty}\right)$;

$-s$ is the power parameter describing the rate of the resistance increase.

For the chosen temperature, it is noticed that the increase of bond strength starts to stabilize after approximately 2.5 hours. After this time, the material can be considered fully cured and no further increase of bond strength can be achieved.

\section{Conclusions}

In this paper a comparison of bond properties of post-installed rebars subjected to elevated temperatures determined through different test apparati is presented. Additionally, the influence of heating procedure is investigated.

It was observed that, despite the different test apparati and design of concrete mix, both CSTB and PoliMI laboratories present very similar results in terms of decay of bond strength, showing a maximum difference lower than $5 \%$. Consequently, a good reproducibility of the results for tests where the load is applied prior to temperature increase ('constant load' procedure) is observed. Such finding represents an important benchmark for the testing procedure reported in EAD 330087 [12].

Nonetheless, significant differences in terms of thermal gradients along the rebar length were detected. At CSTB, thermal gradients appear higher especially near $100^{\circ} \mathrm{C}$, where the difference between the two measurement points at the top and and at the bottom of the rebar can reach $50^{\circ} \mathrm{C}$. By performing drying tests on the concrete specimens, water content is excluded as main responsible. However, results of mercury intrusion porosimetry tests suggest that differences in porosity and pore diameters may be responsible for such difference.

When the temperature is increased to a target value and kept constant prior to load increase ('stabilized temperature' procedure), test results show that the initial stiffness of the system does not seem to be affected by the heating rate (and, consequently, by the exposure time). However, by comparing results obtained with the two procedures for the same target temperature, it is shown that, in the 'stabilized temperature' procedure, bond strength significantly increases when decreasing the heating rate. Such increase shows a convergence towards an asymptotic value, which can be assumed to correspond to full curing of the bonding agent.

It is remarked that such results cannot be generalized to any other temperature. In fact, when approcing higher temperatures different phenomena, such as water vaporization, may affect the results, which may result in an evolution of the bond strength increase with exposure time different from the one reported for the investigated temperature. Further investigation is required to properly assess such effects, in particular with respect to very fast heating rates, which are typical of a fire event in regions close to the exposed surface of the concrete member. 


\section{Acknowledgements}

The support to the experimental work provided by both Polytechnic of Milan and CSTB Laboratories is gratefully acknowledged. Special thanks to eng. Andrea Consiglio for his support in the setting up and execution of the tests and to prof. Cristina Tedeschi for her support in mercury intrusion porosimetry testing.

\section{Conflict of interest}

The authors declare that they have no potential conflict of interest with respect to the scope or to the content of the present work.

\section{References}

1. R.D. Adams, J. Coppendale, V. Mallick and H. Al-Hamdan "The effect of temperature on the strength of adhesive joints". International Journal of Adhesion and Adhesives, 12(3):185-190, 1992.

2. Zhou, J., Lucas, J.P. "Hygrothermal effects of epoxy resin. Part I: the nature of water in epoxy". Polymer, 40: 5505-5512, 1999.

3. CEN. EN 1992-1-2. Eurocode 2, Part 1-2 "Design of concrete structures - General rules and structural fire design". Eurocode 2, Part 1-2, CEN, Brussels, Belgium, 2005.

4. EOTA Technical Report 023 "Assessment of post-installed rebar connections". European Organization for Technical Assessment (EOTA), Brussels, Belgium, 2006.

5. Chin, J., Forster, A., Ocel, J., Hartmann, J., Fuchs, P., Hunston, D. "Thermoviscoelastic Analysis and Creep Testing of Ambient Temperature Cure Epoxies Used in Adhesive Anchor Applications". Journal of Materials in Civil Engineering, 22: 1039-1046, 2010.

6. Mindeguia J-C, Pimienta P, Noumowé A, Kanema M. "Temperature, pore pressure and mass variation of concrete subjected to high temperature - Experimental and numerical discussion on spalling risk". Cem Concr Res March , 40(3): 477-487, 2010.

7. N. Pinoteau, P. Pimienta, T. Guillet, P. Rivillon and S. Remond. "Effect of heating rate bond failure of rebars into concrete using polymer adhesives to simulate exposure to fire". International Journal of Adhesion and Adhesives, 31:851-861, 2011.

8. Auer, M., Stempniewski, A. "The influence of the damage state of the surrounding concrete on the bond stress-slip relationship". 4th International Symposium, Fib. Presented at the Bond in Concrete: Bond, Anchorage, Detailing, Brescia, Italy , 44-57, 2012.

9. Omar Moussa, Anastasios P. Vassilopoulos, Julia de Castro, Thomas Keller " Early-age tensile properties of structural epoxy adhesives subjected to low-temperature curing". International Journal of Adhesion and Adhesives, 35: 9-16, 2012.

10. Davide Sciancalepore, Alessandro Simonini "Il fenomeno dello spacco esplosivo del calcestruzzo esposto al fuoco". Thesis manuscript, April 2013.

11. Nicolas Pinoteau "Comportement des Scellements Chimiques d'Armatures Rapportées pour Béton en Situation d'Incendie". Thesis manuscript, June 2013.

12. EOTA EAD 330087-00-06.01 "Systems for post-installed rebar connections with mortar". European Organization for Technical Assessment (EOTA), Brussels, Belgium, 2015

13. Md Jihad Miah, Pierre Pimienta, Héléne Carré, Nicolas Pinoteau, Christian La Borderie "Effect of cement type on pore pressure, temperature, and mass loss of concrete heated up to $800^{\circ} \mathrm{C} "$. Rencontres Universitaires de Génie Civil, Bayonne, France, May 2015.

14. Julien Michels, José Sena Cruz, Rouven Christen, Christoph Czaderski, Masoud Motavalli "Mechanical performance of cold-curing epoxy adhesives after different mixing and curing procedures". Composites, B: 434-443, 2016.

15. G. Muciaccia, A. Consiglio and G. Rosati. "Behavior and design of post-installed rebar connections under temperature". Key Engineering Materials, 11:783-790, 2016.

16. Nicolas Pinoteau, Thierry Guillet, Sébastien Rémond, Pierre Pimienta, Romain Mége "Background on the Fire Evaluation of Post-Installed Reinforcement Bars in Concrete". Proceedings Connections between Steel and Concrete, 2017. 
17. Mohamed Amine Lahouar, Jean-Francois Caron, Nicolas Pinoteau, Gilles Forêt, Karim Benzarti "Mechanical behavior of adhesive anchors under high temperature exposure: Experimental investigation". International Journal of Adhesion and Adhesives, 78:200-211, 2017.

18. Amine Lahouar "Tenue au Feu des Goujons Collés dans le Bois et e Béton". Thesis manuscript, December 2018.

19. G. Muciaccia, A. Consiglio and G. Rosati. "Creep Behavior of Bonded Anchor Under High Sustained Loading at Long Term Temperature". High Tech Concrete: Where Technology and Engineering Meet, 956-964, 2018. 